\title{
Analysis of Gear Wheel Body Influence on Gearing Stiffness
}

\author{
Silvia Medvecká-Beňová ${ }^{1, *}$ \\ 1 Technical University of Košice, Faculty of Mechanical Engineering, Department of Construction, Automotive and Transport Engineering, Letná 9, Košice
}

\begin{abstract}
The development of modern machinery and production facilities is characterized by constantly increasing performance parameters at the decreasing weight of the machine. It is also a characteristic of the design of the body shape of larger wheel gears. The lowering the weight of the body of wheel gears affects to the deformation and mesh stiffness of the gearing. This work is dealing with the design of large gears, which is assessed based on tooth deformation and mesh stiffness of gearing. The task of this work is decide the design of a body of big gear wheels made as monolithic unit, relative on tooth deformation in meshing, accordingly on the mesh stiffness of gearing. Tooth deformation is calculated by finite element method.
\end{abstract}

Keywords: spur gear, tooth deformation, body of wheel gear, mesh stiffness, FEM.

\section{Introduction}

The most important mechanism in industrial machinery, automotive applications, and our daily lives is a gearbox. Gearbox to transmit power, provide rotational speed changes and/or change the direction of motion. Vibrations of the gear pair are always caused by external excitations from fluctuation of applied torque and input operating speed [12], and by internal excitations from time-varying cyclic mesh stiffness and transmission errors $[4,6]$.

In gear design is a major concern gear noise. The main source of gear noise is the appearance of non-uniform rotations of the gear wheels. Periodic changes the stiffness of the teeth during meshing in gear is a mainly effects of the noise in the transfer. Reducing the dynamic loading and noise of gear systems has been an important concern in gear design [7].

You could determine the mesh stiffness by measurement. As it cannot be measured directly, usually the transmission error over the angular position is recorded at a constant torque (and sufficiently slow rotational speed where dynamic effects can be neglected). From this you can determine the mesh stiffness, but you would have to subtract the effects from other compliances you are not intending to be included in your mesh stiffness, like shaft torsion. Another way is to measure the resonance of the gear pair. You can slowly accelerate the gears from 0 rpm until you pass the main resonance (parameter-excitation with meshing frequency) and measure the angular vibrations. Provided you have a dynamical model of the gear stage, you could fit the stiffness parameters to match the measurement. This usually works for the mean mesh stiffness, but won't give you the exact variations over the angular position.

You could also determine the mesh stiffness by simulating the proposed measurements with a finite element model. It is this method was used to solve the 
problem.

The work is devoted to the analysis of influence of the body wheel shape on the tooth stiffness. The problem is solved for spur gears. As the basis for calculating the tooth stiffness are results of teeth deformation. The teeth deformation has be solution problem by finite element method.

\section{Design of Large-dimensional Gear Wheels Body Shape}

When designing big gear wheel shapes, the goal is to achieve the smallest wheel weight. However, the reduction of the load-bearing cross-sections is usually limited by the requirement for sufficient stiffness of the bodies. In the case of gears it is a gear mesh stiffness.

Large-dimensional gear wheels can be made as monolithic one, the most commonly are a forged and cast gear wheels.

Spur gears with a diameter of 200 to $500 \mathrm{~mm}$ are produce of forged blanks most commonly. Fig. 1 shows the most commonly used design of forged gear wheel. Some parameters are dimensioned there, the size of which must be optimized.
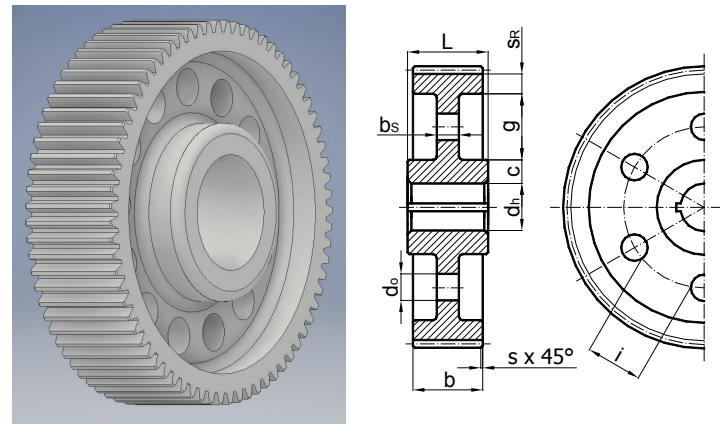

Fig. 1: Design of body gear wheel of a forged spur gears.

Larger spur gears with a diameter of over $500 \mathrm{~mm}$ may be produce as a cast blanks. Fig. 2 shows the most commonly used design of cast blanks wheel gear.

But striving to improve the design of the gears, aimed at reducing the dimensions and weight, has be led to the used of gears with thin-walled gear rim and with thin gear rim. The wheel rim thickness $\left(S_{R}\right)$ and wheel web thickness (bs) are important parameters which influence of weight of gear wheel. In the next section, the paper will focus on the influence of wheel rim and web parameters on the tooth stiffness of spur gears.
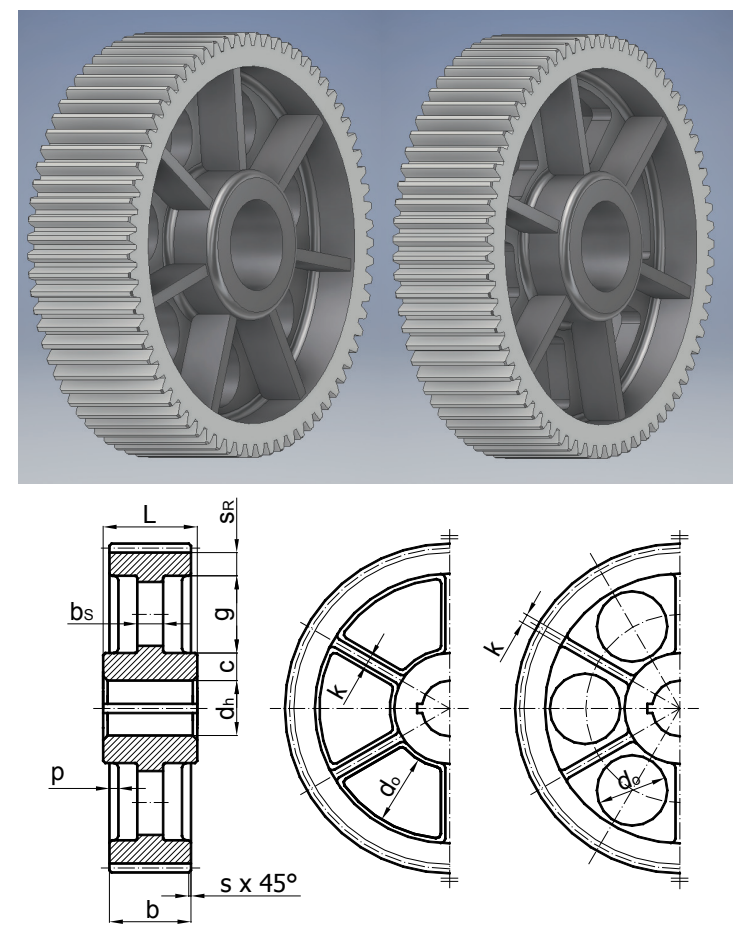

Fig. 2: Design of body gear wheel of cast blanks of the spur gears

\section{Teeth Deformation and Teeth Stiffness of Spur Gears}

The teeth of the gear wheels are deformed due to load. This is the cause of some negative but also positive consequences. Therefore, the knowledge of the deformation properties of the teeth is very important $[6,8]$. Deformation of teeth is usually expressed quantitatively as a teeth stiffness during by gear mesh [4]. In general, stiffness defined as the ratio of load to deformation. The stiffness of the tooth is defined as the force per unit width, which is necessary for the deformation about $1 \mu \mathrm{m}[5,12]$.

The theoretical determination of the teeth deformation is difficult due to the complex shape of the gear teeth. In recent years, the question of teeth deformation has been solved using modern methods of calculation, for example by a finite element method. In this work, the finite element method is used to determine the teeth deformation. To determine the computer model for studying deformation of the teeth using FEM was necessary to determine the material constants, define the type of finite element, and selecting appropriate boundary conditions (geometry and load). We will focus on the value of total deformation " $\delta$ " in the direction of load forces, if the force is applied to the 
head of the tooth (the largest bend) according to Fig. 3.

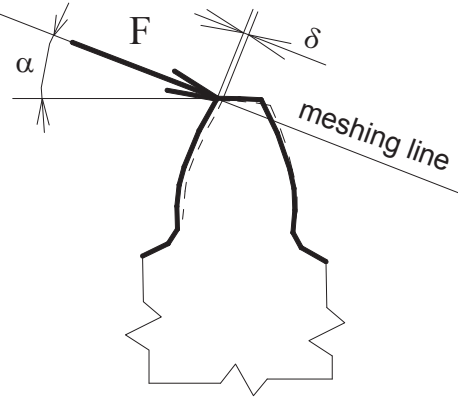

Fig. 3: Face of pressure line.

On the basis of the teeth deformation, the stiffness of the teeth is calculated. In general the teeth stiffness $\mathrm{C}$ is defined by equation (1):

$c=\frac{w}{\delta}$

where $c$ - teeth stiffness $[\mathrm{N} / \mathrm{mm} . \mu \mathrm{m}], w$ - load across the width of the teeth $[\mathrm{N} / \mathrm{mm}], \delta$ - teeth deformation $[\mu \mathrm{m}]$.

The teeth stiffness values are the basis for assessing the suitability of design of the wheels in this paper.

\section{Influence of the Wheel Web Thickness and Wheel Rim Thickness on the Teeth Stiffness}

According to STN 014686 (Strength calculation of spur and bevel gears), the value of wheel rim must be greater than value 3.5 multiple of $m_{n}$, where $m_{n}$ is the standard module of gearing $\left(\mathrm{S}_{\mathrm{R}} \geq 3.5 \mathrm{~m}_{\mathrm{n}}\right)$.

The impact of the rim thickness (value $\mathrm{S}_{\mathrm{R}}$ in Fig. 4) on the deformation and stiffness of the tooth will be determined on the spur gear with a number of teeth of $\mathrm{z}=61$ and a module $\mathrm{m}_{\mathrm{n}}=4 \mathrm{~mm}$, a tooth width $\mathrm{b}=80 \mathrm{~mm}$ and load $\mathrm{F}=5000 \mathrm{~N}$. The thickness of the wheel rim is changed from the value $\mathrm{S}_{\mathrm{R}}=1.75 \mathrm{~m}_{\mathrm{n}}, 2.5 \mathrm{~m}_{\mathrm{n}}, 3.5 \mathrm{~m}_{\mathrm{n}}, 5 \mathrm{~m}_{\mathrm{n}}, 8 \mathrm{~m}_{\mathrm{n}}$ to the full body of the wheel. The other geometric dimensions of the wheels do not change.

These results are determined by the finite element method and are processed in the graph in Fig. 5. As the results show, decreasing the thickness of the rim wheel is increases the tooth deformation and the tooth stiffness is decreases. The minimum permissible thickness of the wheel rim according to [13] is a $S_{R}=3.5 m_{n}$, where $m n$ is a module of the gear wheel. Thickness of wheel rim less than value $3.5 \mathrm{~m}_{\mathrm{n}}$
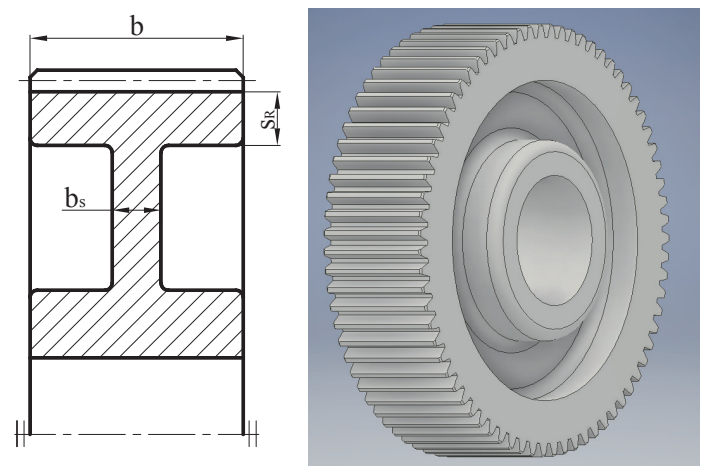

Fig. 4: Design of gear wheel for reviewing influence of thickness of the wheel rim.

has more affects to the tooth deformation and stiffness. Thickness of wheel rim bigger than value $3.5 \mathrm{~m}_{\mathrm{n}}$ has smaller affects to the teeth deformation and stiffness.
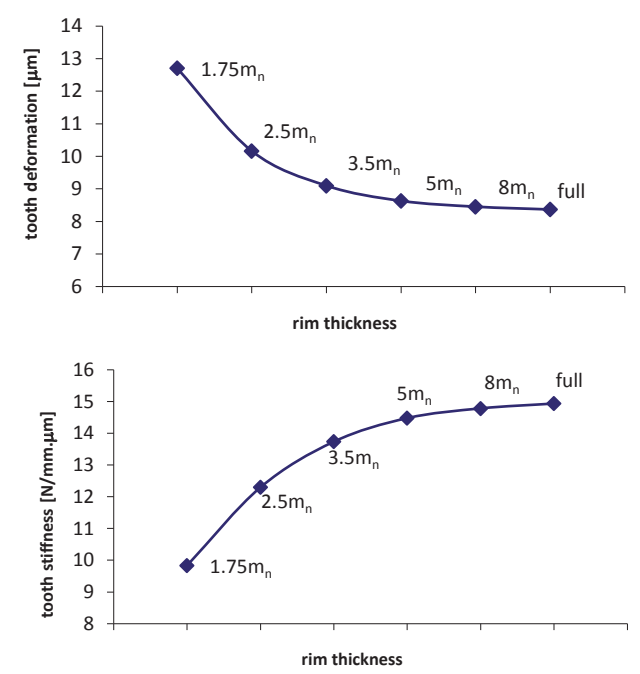

Fig. 5: Influence of wheel rim on the teeth deformation and teeth stiffness.

The impact of the rub thickness (value bs - Fig.4) on the teeth stiffness will be determined on the spur gear with a number of teeth of $\mathrm{z}=61$ and a module $\mathrm{m}_{\mathrm{n}}=4 \mathrm{~mm}$ and $\mathrm{a}$ tooth width $\mathrm{b}=80 \mathrm{~mm}$, the value of wheel rim is $\mathrm{S}_{\mathrm{R}}=22 \mathrm{~mm}$. The web is located at the center of the gear wheel width and its thickness will change from $10 \mathrm{~mm}$ to the $80 \mathrm{~mm}$, when it is a full gear wheel without a web. The force is applied to the head of the tooth (the largest bend) according to Fig. 3 and the value of load across the width of the tooth is a $\mathrm{w}=40 \mathrm{~N} / \mathrm{mm}$.

The results of the tooth stiffness distribution along 
the gear wheel width and solution by finite element method are shown in Fig. 6. In this figure is the local influence of the tooth stiffness with is distribution on the gear width.

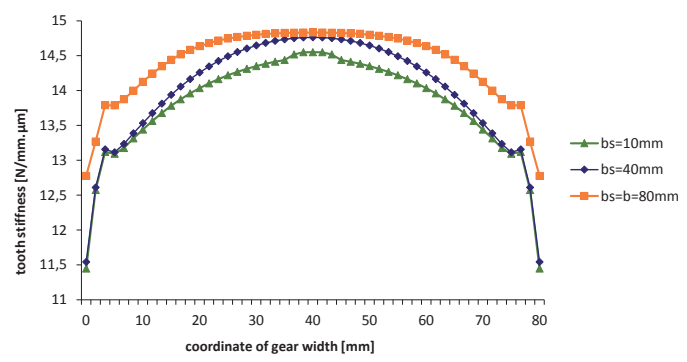

Fig. 6: The teeth stiffness distribution along the gear wheel width.

The tooth deformation is reduced and the tooth stiffness is expanded, due to the increase in the thickness of the wheel web located at the center of the gearing width, it is show in Fig. 7. This change in tooth deformation and tooth stiffness is more pronounced to the first half of gearing width.
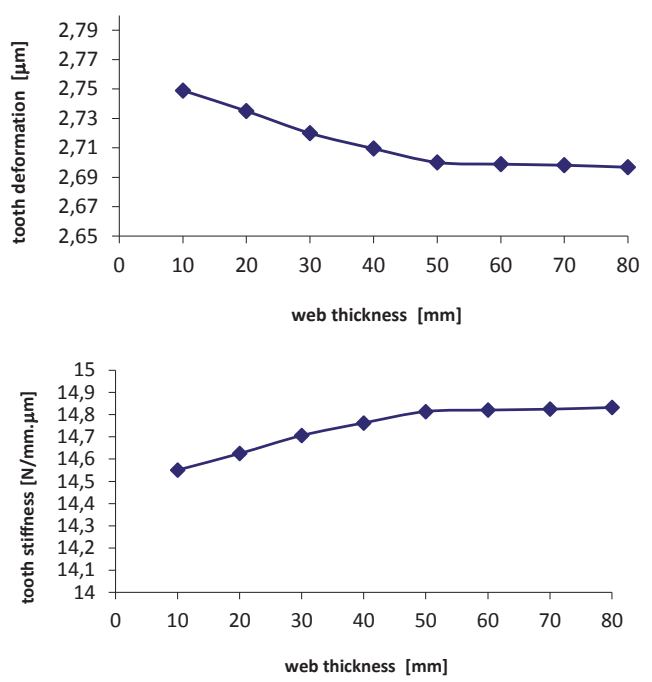

Fig. 7: Influence of wheel web on the teeth deformation and teeth stiffness.

\section{Influence of Body Gear Wheel of Cast Blanks in the Teeth Deformation}

This problem solution by spur gear with a number of teeth of $\mathrm{z}=71$ and a module $\mathrm{m}_{\mathrm{n}}=7 \mathrm{~mm}$, a tooth width $b=150 \mathrm{~mm}$, the thickness of the wheel rim $\mathrm{S}_{\mathrm{R}}=25 \mathrm{~mm}$ and thickness of the wheel web $\mathrm{b}_{\mathrm{s}}=30 \mathrm{~mm}$. The force $\mathrm{F}=15000 \mathrm{~N}$ is applied to the head of the tooth (the largest bend) according to Fig. 3 and the value of load across the width of the tooth is a $\mathrm{w}=100 \mathrm{~N} / \mathrm{mm}$. The maximum deformation of the tooth solved on the models of the spur gears is discussed in Table 1.

The results shown in Table 1 are graphically illustrated in Fig. 8. This figure shows the effect of weight loss of spur gear wheel on tooth deformation. Wheel number 4 is chosen as the zero-drop wheel, because its weight is the largest of the solved models. In fact, however, the wheel number 4 has a $50.5 \%$ less weight compared to the full wheel. The graph shows that as the material decreases, the teeth deformation increases.

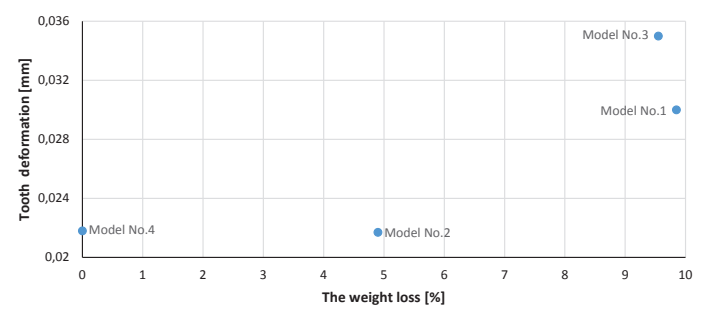

Fig. 8: The effect of material loss on the maximum tooth deformation.

\section{Conclusions}

Steadily increasing performance factors in decreasing the weight of the device is characterized development of the modern machinery and means of production. It is a feature of the design for choice of the shape of the body larger gear. Lightening of body wheel gears has effects on the deformation and stiffness of the teeth. Teeth stiffness is decreases with the decrease in thickness of the wheel rim. Teeth stiffness is not constant even after the width of tooth. If the ends of mesh contact line identic of the edge of the teeth, the teeth stiffness is less on this locality. The teeth deformation is reduced and the teeth stiffness is expanded, due to the increase in the thickness of the wheel web located at the center of the gearing width. The localization of wheel web has a influence of the teeth stiffness. One factor in assessing the appropriate shape of large cast spur gear wheel is to assess this suitability for deformation and stiffness of teeth. 
Tab. 1: Maximum tooth deformation in the load area for designed cast-cast models of spur gears wheels.

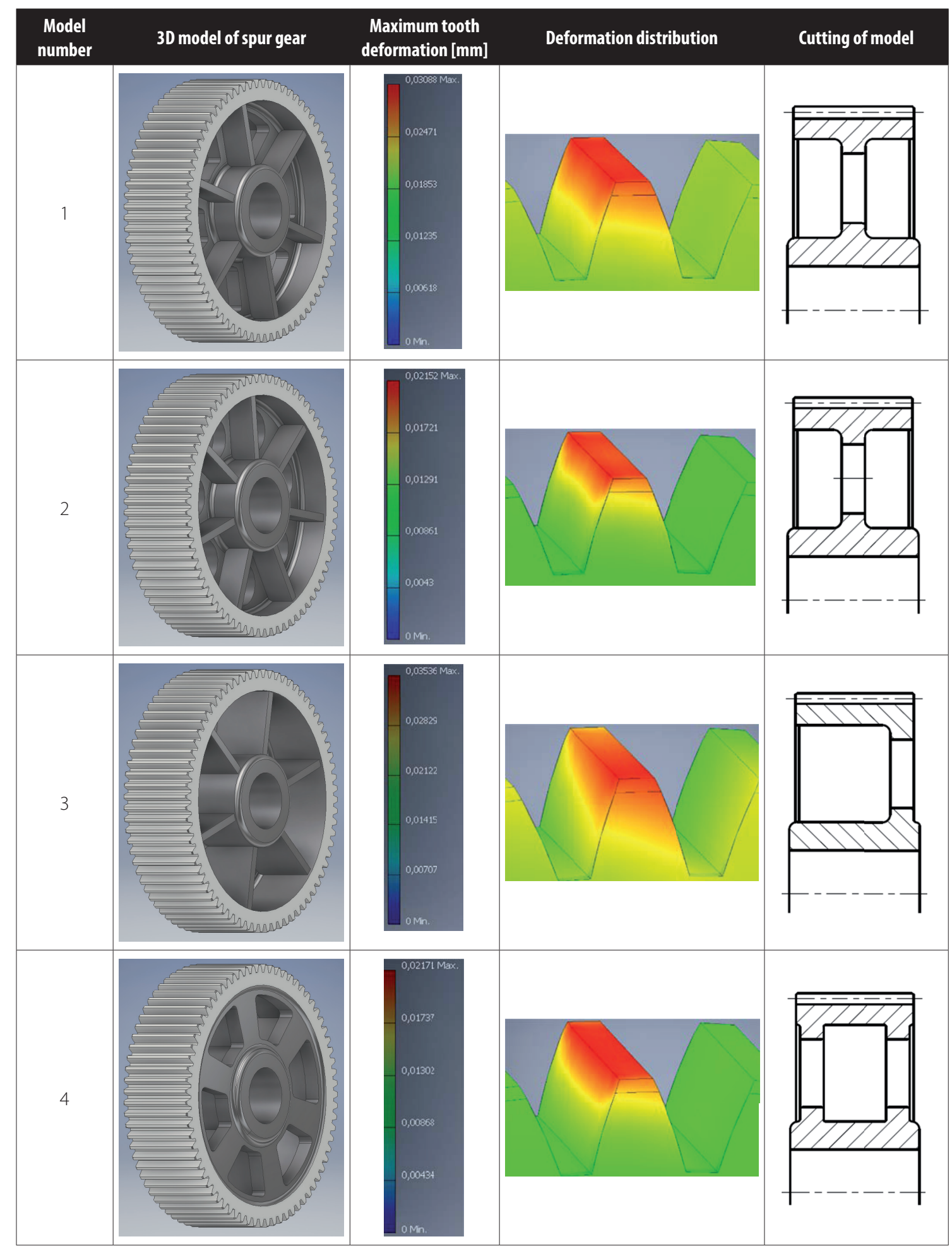




\section{Acknowledgments}

This paper was written in the framework of Grant Project VEGA: "11/0473/17-Research and development of technology for homogeneous charge self-ignition using compression in order to increase engine efficiency and to reduce vehicle emissions".

\section{References and Notes}

[1] Batsch, M., Surface strength of novikov covexo-concave gear, Scientific Journal of Silesian University of Technology. SeriesTransport. 90 (2016) 17-24.

[2] Cooley, CH. G., Liu, Ch., Dai, X., Parker, R. G. Gear tooth mesh stiffness: A comparison ofcalculation approaches, Mechanism and Machine Theory. 105 (2016) 540-553.

[3] Czech, P. Diagnosis of Industrial Gearboxes Condition By Vibration and Time-Frequency, Scale-Frequency, FrequencyFrequency Analysis. Metalurgija, Volume: 51, 4 (2012) 521 524.

[4] Czech, P., Wojnar, G., Warczek, J. (2014). Diagnozowanie uszkodzeń wtryskiwaczy w silnikach spalinowych pojazdów przy użyciu analizy bispektrum i radialnych sieci neuronowych. Logistyka, 3, 1181-118.

[5] Czech, P., Łazarz, B., Madej, H. (2010). The influence of the pressure in tyres and the load of the car on the delay and the braking distance of a motor-car without ABS system. Scientific Journal of Silesian University of Technology. Series Transport. Vol. 69, p. 21-28. ISSN: 0209-3324.

[6] Femandez del Rincon, A., Viadero, F, et al. (2013). A model for the study of meshing stiffness in spur gear transmissions. Mechanism and Machine Theory, 61, 30-58.

[7] Chen, Z., Shao, Y. Dynamic simulation of spur gear with tooth root crack propagating along tooth width and crack depth, Engineering Failure Analysis 18 (2011), 2149-2164.

[8] Medvecká-Beňová, S. (2015). Deformation and stiffness of spur gear teeth and trheir influence on gear noise. Scientific Journal of Silesian University of Technology: Series Transport, 89, 101-107.

[9] Medvecká-Beňová, S., Vojtková, J. (2014). Aplication of asymetric profile in gearing in gearings with eccentric gears. Zeszyty naukowe Politechniki Śląskiej, 85, 1925, 89-93.

[10] Medvecká-Beňová, S., Frankovský, P., Grega, R. Influence gearing parameters on the tooth deformation of spur gears. Applied Mechanics and Materials. 816 (2015): 27-30.

[11] Noga, S., Markowski, T., Bogacz, R. Method of determining thenormal modes of toothed gears with complex geometry, Scientific Journal of Silesian University of Technology. Series Transport. 89 (2015) 119-127.

[12] Sika, G., Velex, P. Analytical and numerical analysis of gears in the presence of engine acyclism, Journal of Mechanical Design — the ASME 130 (2008), 1-6.

[13] Standard STN 014686

\section{Biographical notes}

Silvia Medvecká-Beňová, doc. Ing. PhD.: she received M.S. degree from the Technical University of Košice in 1997, PhD. degree received in Machine Parts and Mechanisms from the Technical University of Košice in 2002. She is an associated professor of the Department of Construction, Automotive and Transport Engineering of the Faculty of Mechanical Engineering, Technical University of Košice. Her research interests include mesh stiffness and deformation of gearing, noise of gearbox, stress of gearing, gears with a continuous change of speed ratio. 